\title{
Technetium-99m Labeled Fatty Acid Analogues for SPECT Imaging in Heart and Liver
}

\author{
Huahui Zeng ${ }^{1,2 *}$, Tingting Zhang ${ }^{1}$, Fahuan Song ${ }^{2}$ and Xiangxiang $\mathbf{W u}^{1 *}$ \\ ${ }^{1}$ Pharmacy College \& Scientific Research Department, Henan University of Traditional Chinese Medicine, Zhengzhou, 450046, China \\ ${ }^{2}$ Department of Nuclear Medicine, Second Affiliated Hospital of Zhejiang University School of Medicine, Hangzhou 310009, China
}

\begin{abstract}
Fatty acid imaging can measure fatty acid oxidation rates in heart or liver for research applications in animals and clinical applications in humans with metabolic disorders. Recent advances in fatty acid imaging using single photon emission computed tomography (SPECT) include the wide applications of the tracer beta-methyl-p-[123]]-iodophenylpentadecanoic acid (BMIPP) to assess ischemic heart disease, cardiomyopathies, myocarditis, acute coronary syndrome, and heart failure and the design of new technetium-99m labeled tracers. In this mini-review article, several technetium-99m labeled fatty acid analogues as SPECT tracers are characterised, and the uptake of tracers, clearance from tissues, and mechanism of metabolism are discussed in detail. We subsequently summarized that some essential modification in fatty acid analogue structure can exert profound differences in the biodisposition and specificity of these tracers to improve the uptakes of fatty acids and prolong theirs retention in myocardium/hepatocyte. Thus, technetium$99 \mathrm{~m}$ labeled fatty acid analogues have significant potential to play an important role as clinical SPECT traces of fatty acid oxidation in cardiovascular diseases, liver, and other applications in skeletal muscle and tumors.
\end{abstract}

Keywords: SPECT; Technetium-99m; Fatty acid; Beta-oxidation; Fatty acid oxidation; BMIPP

\section{Introduction}

Fatty acids are important substrates for energy metabolism under aerobic conditions, particularly in the heart, liver, skeletal muscle, tumors and so on [1-3]. After uptake by the tissues, fatty acids enter mitochondrial beta-oxidation by removing two-carbon units or are incorporated into the triglyceride pool $[4,5]$. In the myocardium, more than $80 \%$ of fatty acids uptake is directly oxidized and only a small fraction is stored as triglycerides after fasting $[5,6]$. Whereas in liver, medium chain fatty acids more easily enter the mitochondria without the use of carnitine shuttle system and are predominantly metabolized via beta-oxidation [7]. Energy metabolic pathways in heart and liver are sensitively regulated and immediately reflect any pathological changes or abnormalities. So monitoring of Fatty acids metabolism provides substantial information about the disease state and therapeutic progress. Therefore, the beta-oxidation of fatty acid can be a marker for energy metabolism of the heart and liver. For past decades, fatty acids were radiolabeled with various radionuclides to evaluate fatty acid metabolism using single photon emission computed tomography (SPECT) and positron emission tomography (PET), which can provide an easy visualization of tissues energy metabolism in a noninvasive and quantitative manner.

The currently available tracers for metabolic imaging comprise several fatty acid tracers, ${ }^{18}$ Ffluorodeoxyglucose (FDG) for the evaluation of glucose metabolism and ${ }^{11} \mathrm{C}$-acetate for the assessment of oxygen consumption [4]. Of these tracers, only ${ }^{123}$ I-labelled fatty acid-based SPECT tracers are currently in routine practice in some of the European countries and Japan, but not in other countries [4,8]. As long chain fatty acid PET radiotracer, $1-\left[{ }^{11} \mathrm{C}\right]$ Palmitate showed short physical half-life (20.4 min) and biexponential clearance in heart with rapid washout via beta-oxidation and slow turnover of triglycerides [9]. In addition, the quantitation of the dynamic PET images is not possible in ischemic myocardium because of the rapid diffusion rates of the oxidation product ${ }^{11} \mathrm{CO}_{2}$ and unoxidized ${ }^{11} \mathrm{C}$-palmitate, thereby confounding the model fit $[10,11] .16-\left[{ }^{18} \mathrm{~F}\right]$ Fluoropalmitic acid (FPA) showed a same initial myocardial uptake and a longer retention than 1-[ $\left.{ }^{11} \mathrm{C}\right]$ Palmitate. $14-\left[{ }^{18} \mathrm{~F}\right]$ Fluoro-6-thiaheptadecanoic acid (FTHA) and $18-\left[{ }^{18} \mathrm{~F}\right]$ fluoro-4-thia-oleate (FTO), ${ }^{18} \mathrm{~F}$-labeled thia fatty acids as metabolically trapped tracers of fatty acid oxidation, were designed for prolonged myocardial retention [8]. Nevertheless, FTHA is the mostinvestigated thia fatty acid PET tracer in clinical trials in heart [12], liver [1,13], skeletal muscle [2], tumor [3], and brain [14]. However, short half-life of ${ }^{18} \mathrm{~F}(110 \mathrm{~min})$ and rapid washout of those tracers in heart were unfavourable for clinical diagnosis. Thus, the lack of ${ }^{18} \mathrm{~F} /{ }^{11} \mathrm{C}$-labeled fatty acid-based PET tracers motivated further tracer development to improve myocardial uptake and retention. Fatty acid imaging has a long history, with iodinated fatty acids being labeled in the 1960s for heart imaging [15]. Among those tracers, $15-\left(p-\left[{ }^{123} \mathrm{I}\right]\right.$ iodophenyl)-3-methylpentadecanoic acid (BMIPP) [16] has been studied extensively in clinical settings as well as in animal experiments. This compound is designed for SPECT imaging, which requires long myocardial retention of the tracer for good image quality [4]. However, the high cost of the accelerator-produced radionuclide iodine-123 and the nuclear properties of shedding radioiodine have constrained the application of those tracers. A Tc-99m-labeled fatty acid analogue would be highly desirable because of the ideal nuclear properties of this radionuclide $\left(141 \mathrm{keV}, t_{1 / 2}=6 \mathrm{~h}\right)$ and its easy availability through the ${ }^{99} \mathrm{Mo} /{ }^{99 \mathrm{~m}} \mathrm{Tc}$ generator system whenever needed.

In the past decades, various Tc-99m complexes incorporating fatty acid analogues have been developed, but no compound has potential use in clinical practice for poor myocardial uptake and rapid washout from heart. Recently, [ $\left.{ }^{99 \mathrm{~m}} \mathrm{Tc}\right]-M A M A-h e x a d e c a n o i c$ acid ( $\left.{ }^{99 \mathrm{~m}} \mathrm{Tc}-\mathrm{MAMA}-\mathrm{HDA}\right), \quad[17] \quad\left[{ }^{99 \mathrm{~m}} \mathrm{Tc}\right](\mathrm{CO})_{3}-15-[\mathrm{N}$-(acetyloxy)-

*Corresponding authors: Huahui Zeng, Department of Nuclear Medicine, Second Hospital of Zhejiang University School of Medicine, 88 Jiefang Road, Hangzhou, Zhejiang 310009, China, Tel: 86-0571-87783659; Fax: 86-0571-87767148; E-mail huahuizeng@gmail.com

Xiangxiang Wu, Science \& Technology Department, Henan University of Traditional Chinese Medicine, Jinshuidong Road Boxue Road, Zhengzhou, Henan 450008, China, Tel: 86-371-65962546; Fax: 86-371-65962546; E-mail: wuxx-415@126.com

Received March 19, 2014; Accepted May 15, 2014; Published May 17, 2014

Citation: Zeng H, Zhang T, Song F, Wu X (2014) Technetium-99m Labeled Fatty Acid Analogues for SPECT Imaging in Heart and Liver. Med chem 4: 481-486. doi:10.4172/2161-0444.1000182

Copyright: @ 2014 Zeng $\mathrm{H}$, et al. This is an open-access article distributed under the terms of the Creative Commons Attribution License, which permits unrestricted use, distribution, and reproduction in any medium, provided the original author and source are credited. 
2-picolylamino]pentadecanoic acid $\quad\left({ }^{99 \mathrm{~m}} \mathrm{Tc}-\mathrm{PA}-\mathrm{PA}\right), \quad[18] \quad\left[{ }^{99 \mathrm{~m}} \mathrm{Tc}\right]$ cyclopentadienyltricarbonyltechnetium pentadecanoic acid ${ }^{99 \mathrm{~m}} \mathrm{Tc}-$ CpTT-PA) [19] and 16-cyclopentadienyl tricarbonyl technetium99m 16-oxo-hexadecanoic acid ( ${ }^{99 \mathrm{~m}} \mathrm{Tc}-\mathrm{CpTT}$-16-oxo-HDA) [20] showed higher initial heart uptakes than early ${ }^{99 \mathrm{~m} T c-l a b e l l e d ~ f a t t y}$ acid analogues, such as ${ }^{99 \mathrm{~m}} \mathrm{Tc}-\mathrm{BAT}$-pentadecanoic acid, ${ }^{99 \mathrm{~m}} \mathrm{Tc}$-labelled DTPA or EDTA fatty acids [21,22]. Those Tc-99m-labeled fatty acid analogues were analyzed using the metabolites in rodent heart or urine samples to elucidate whether those analogues are recognized and metabolized by heart via beta-oxidation. ${ }^{99 \mathrm{~m} T c-M A M A-H D A},{ }^{99 \mathrm{~m}} \mathrm{Tc}-$ PA-PA, ${ }^{99 \mathrm{~m}} \mathrm{Tc}$-CpTT-PA and ${ }^{99 \mathrm{~m}} \mathrm{Tc}$-CpTT-16-oxo-HDA were primarily metabolized to ${ }^{99 \mathrm{~m}} \mathrm{Tc}-\mathrm{MAMA}$-butyric acid, ${ }^{99 \mathrm{~m}} \mathrm{Tc}(\mathrm{CO})_{3}$ - $[\mathrm{N}$-(acetyloxy)2-picolylamino]pentanoic acid, ${ }^{99 m} \mathrm{Tc}-\mathrm{CpTT}$-propionic acid and 99mTc-CpTT-4-oxo-butyric acid via beta-oxidation in myocardium, respectively. All those tracers were developed with long linear chains fatty acids incorporating various ${ }^{99} \mathrm{~m}$ Tc-labeled bifunctional chelating groups [23], which showed different accumulation and rapid washout of the tracers in heart or liver. However, a good quality of ${ }^{99 \mathrm{~m}} \mathrm{Tc}$ labeled fatty acid-based SPCET imaging requires that the structure modification of fatty acid should conform to its natural properties and the metabolism mechanism in heart, liver and other tissues. In this mini-review, we intend to introduce the incremental development and highlight promises of ${ }^{99 \mathrm{~m}} \mathrm{Tc}$-labeled fatty acids as potential tracer for fatty acid oxidation imaging in heart and liver.

\section{9mTc-MAMA-fatty Acid Analogues}

Development of a ${ }^{99 \mathrm{~m} T c-l a b e l e d ~ f a t t y ~ a c i d ~ a n a l o g u e ~ i s ~ o f ~ i n t e r e s t, ~}$ as ${ }^{99 \mathrm{~m}} \mathrm{Tc}$ is logistically advantageous over the cyclotron-produced ${ }^{11} \mathrm{C}$ and ${ }^{123} \mathrm{I}$. [ ${ }^{99 \mathrm{~m} T \mathrm{Tc}}$-MAMA-hexanoic acid $\left.{ }^{{ }^{99} \mathrm{~m}} \mathrm{Tc}-\mathrm{MAMA}-\mathrm{HA}\right)$ (Figure 1a) was the first ${ }^{99 \mathrm{~m}} \mathrm{Tc}$-labeled MAMA medium-chain fatty acid analogues that reflected beta-oxidation activity of the liver in rats [24]. After intravenous administration of ${ }^{99 m}$ Tc-MAMA-HA, the tracer showed high initial accumulation in the liver followed by clearance of the radioactivity in the urine. On the basis of these findings, [99m Tc]-MAMA-dodecanoic acid ( ${ }^{99 \mathrm{~m} T c-M A M A-D A)}$ and ${ }^{99 \mathrm{~m} T \mathrm{Tc}-}$ MAMA-HDA (Figure 1a) were prepared using the MAMA ligand incorporating the omega-position of long-chain fatty acid analogues as a chelating group for technetium- $99 \mathrm{~m}$ that reflected beta-oxidation of fatty acid in the heart [17]. In biodistribution studies, ${ }^{99 \mathrm{~m}}$ Tc-MAMAHDA showed a high initial uptake followed by a rapid clearance from the heart of normal rats. The maximum heart to blood ratio was 3.6 at 2 min postinjection (pi) of ${ }^{99 \mathrm{~m}} \mathrm{Tc}-\mathrm{MAMA}-\mathrm{HDA}$, which was almost half the value of that of [ $\left.{ }^{125} \mathrm{I}\right]$-IPPA. The kinetics of the clearance of radioactivity from the heart were very similar between [99m $\mathrm{Tc}$ ] MAMAHDA and $\left[{ }^{125} \mathrm{I}\right]$-IPPA. In sum, ${ }^{99 \mathrm{~m}} \mathrm{Tc}$-labeled MAMA medium-chain fatty acid analogue is peculiarly propitious for hepatobiliary imaging, while ${ }^{99 \mathrm{~m}} \mathrm{Tc}$-labeled MAMA long-chain fatty acid analogue is optimal for myocardial imaging. Furthermore the tracers are metabolized via beta-oxidation in the heart and the liver.

\section{${ }^{99 m}$ Tc-CpTT-fatty Acid Analogues}

A series of radiotracers, ${ }^{99 \mathrm{~m} T c-C p T T-f a t t y ~ a c i d ~ a n a l o g u e s ~(F i g u r e ~}$ $1 \mathrm{~b})$, were prepared in high radiochemical yield ( $\sim 63 \%$ decay-corrected) by a double ligand transfer reaction between the ferrocene adduct of fatty acid methyl ester and $\mathrm{Na}^{99 \mathrm{~m}} \mathrm{TcO}_{4}$ in the presence of $\mathrm{Cr}(\mathrm{CO})_{6}$ and $\mathrm{CrCl}_{3}$, followed by hydrolysis of the methyl ester group. Those radiotracers were shown to be chemically stable when incubated in serum. 8-Cyclopentadienyltricarbonyl technetium-99m 8-oxooctanoic acid ( ${ }^{99 \mathrm{~m}}$ Tc-CpTTOA) [25] was metabolized to 4-cyclopentadienyl tricarbonyl technetium-99m 4-oxobutanoic acid ( ${ }^{99 m}$ Tc-CpTTBA) via beta-oxidation in the liver (Figure $1 \mathrm{~b}$ ), which supported that the beta-oxidation was the main metabolic pathway of this medium chain fatty acid analogue. Planar images of rats injected with ${ }^{99 \mathrm{~m} T c-C p T T O A}$ showed accumulation of the radioactivity in the liver, kidneys, and bladder with rapid hepatic clearance as a function of time. On the basis of these findings, ${ }^{99 \mathrm{~m}} \mathrm{Tc}-\mathrm{CpTT}-\mathrm{PA}$ [19] and ${ }^{99 \mathrm{~m}} \mathrm{Tc}-\mathrm{CpTT}-16-$ oxo-HDA [20] were prepared as long chain fatty acid analogues for energy production in the myocardium (Figure $1 \mathrm{~b}$ ). Biodistribution of ${ }^{99 \mathrm{~m}} \mathrm{Tc}$-CpTT-PA and ${ }^{99 \mathrm{~m}} \mathrm{Tc}$-CpTT-16-oxo-HDA in rats or mice showed high radioactivity accumulation in heart with rapid clearance and high heart to blood uptake ratios, and the tracers were metabolized to ${ }^{99 \mathrm{~m} T c-C p T T-p r o p i o n i c}$ acid and ${ }^{99 \mathrm{~m} T c-C p T T-4-o x o-b u t y r i c ~ a c i d ~}$ via beta-oxidation in myocardium, respectively. [ $\left.{ }^{99 \mathrm{~m}} \mathrm{Tc}\right] \mathrm{CpTT}-\mathrm{PA}$ was similar to [125I]-IPPA with radioactivity uptakes in the heart after $1 \mathrm{~min}$ pi. ${ }^{99 \mathrm{~m}} \mathrm{Tc}$-CpTT-PA showed a slow blood clearance at earlier pi time, whereas a gradual increase in radioactivity in the blood was observed with [ $\left.{ }^{125} \mathrm{I}\right]$-IPPA from 2 to $30 \mathrm{~min}$ pi. In contrast, the radioactivity levels in the liver remained unchanged after injection of [125I]-IPPA, whereas ${ }^{99 \mathrm{~m}} \mathrm{Tc}$-CpTT-PA showed a gradual increase with times. In addition, 15-Cyclopentadienyl tricarbonyl technetium-99m 15-oxopentadecanoyl thiopheneacetic acid ( ${ }^{99 \mathrm{~m} T c-C p T T-15-o x o-P T A) ~[26] ~}$ was synthesized using alkyl group inserted in the beta-position of the chain to interfere with metabolism of the tracer. After intravenous administration of ${ }^{99 \mathrm{~m}} \mathrm{Tc}$-CpTT-15-oxo-PTA, the tracer showed highest uptake of $9.39 \pm 1.10 \% \mathrm{ID} / \mathrm{g}$ at 1 minute and followed by moderate clearance from the rat heart. The maximum heart to blood ratio of (a)<smiles>CN1CC(=O)N2CCS[C@]23O[C@]12SCCN23</smiles>

$$
\begin{aligned}
\mathrm{n}= & 5 ;{ }^{99 \mathrm{~m}} \text { Tc-MAMA-HA } \\
& 11 ;{ }^{99 \mathrm{~m}} \text { Tc-MAMA-DA } \\
& 15 ;{ }^{99 \mathrm{~m}} \text { Tc-MAMA-HDA }
\end{aligned}
$$

(b)

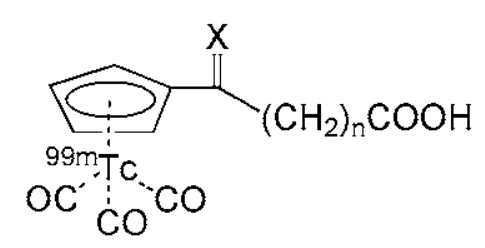

$$
\begin{aligned}
& \mathrm{X}=\mathrm{O}: \mathrm{n}=2 ;{ }^{98 \mathrm{~m}} \mathrm{Tc} \text {-СрТТВА } \\
& =4 ;{ }^{99 \mathrm{~m} T \mathrm{C}-\mathrm{CpTTHA}} \\
& =6 ;{ }^{99 \mathrm{~m}} \mathrm{Tc}-\mathrm{CPTTOA} \\
& \text { =14; }{ }^{99 \mathrm{~m}} \mathrm{~T} \mathrm{c}-\mathrm{Cp} \Pi \mathrm{T}-16 \text {-oxo-HDA } \\
& X=\text { None: } n=13 ;{ }^{99 m} \text { Tc-CpTT-PA }
\end{aligned}
$$

Figure 1: General structure for (a) ${ }^{99 \mathrm{~m} T c-M A M A-f a t t y ~ a c i d s ~ a n d ~(b) ~}{ }^{99 \mathrm{~m} T c-C p T T-f a t t y}$ acids. 
${ }^{99 \mathrm{~m}}$ Tc-CpTT-15-oxo-PTA (5.7 at $15 \mathrm{~min}$ pi) was higher than the tracers, ${ }^{99 \mathrm{~m}} \mathrm{Tc}-\mathrm{CpTT}-\mathrm{PA}$ (4.60 at $10 \mathrm{~min}$ postinjection) and ${ }^{99 \mathrm{~m}} \mathrm{Tc}-\mathrm{CpTT}-16-$ oxo-HDA (3.76 at $30 \mathrm{~min}$ postinjection). Metabolite analysis showed ${ }^{99 m}$ Tc-CpTT-15-oxo-PTA was not metabolized via beta-oxidation in the heart, Thus, the metabolic mechanism is different from that of ${ }^{99 \mathrm{~m}}$ Tc-MAMA-HDA, ${ }^{99 \mathrm{~m}}$ Tc-CpTT-PA and ${ }^{99 \mathrm{~m}}$ Tc-CpTT-16-oxo-HDA.

\section{$\left[{ }^{99 m} \mathrm{Tc}(\mathrm{N})(\mathrm{PNP})\right]^{2+}$ fatty Acid Analogues (PNP=Diphosphane Ligand)}

The ${ }^{99 \mathrm{~m}} \mathrm{Tc}$-labeled fatty acid analogues, $\left[{ }^{99 \mathrm{~m}} \mathrm{Tc}(\mathrm{N})(\mathrm{PNP})(\mathrm{L})\right]^{0 /+}(\mathrm{PNP}$ $=$ diphosphane ligand; $\mathrm{L}=$ dianionic or monoanionic bifunctional fatty acid analogues) (Figure 2), exhibite the asymmetrical structure with a $\mathrm{Tc} \equiv \mathrm{N}$ group surrounded by a tridentate $(\mathrm{PNP})$ and a bidentate $(\mathrm{L})$ chelating fatty acid analogues [27]. The fragment $\left[{ }^{99 \mathrm{~m}} \mathrm{Tc}(\mathrm{N})(\mathrm{PNP})\right]^{2+}$ provides a electrophilic metal moiety for the attachment of the sitespecific group, which were functionalized by appending a bis-mercapto or a dithiocarbamato $\pi$-donor chelating systems to one terminus of the fatty acid analogues. The experiments in rats showed that the ${ }^{99 \mathrm{~m}} \mathrm{Tc}$-labeled monocationic fatty acid $\left[{ }^{99 \mathrm{~m}} \mathrm{Tc}(\mathrm{N})(\mathrm{PNP} 3)(11)\right]^{+}$(Figure 2) were the same as the monocationic tracers, ${ }^{99 \mathrm{~m} T \mathrm{c}-\mathrm{MIBI} \text { and }}{ }^{99 \mathrm{~m} T \mathrm{Tc}-}$ DBODC, with almost identical accumulation in myocardium (Figure

(a)<smiles>O=C(O)CCCCCCCCCNC(=O)C(S)CS</smiles><smiles>O=C(O)CCCCCCCCCNC(=S)S</smiles><smiles>O=C(O)CCCCCCCCCCNC(=S)S</smiles><smiles>O=C(O)CCCCCCCCCCCCCC(=O)NC(CS)C(=O)O</smiles><smiles>COCP(CCO)CN(C[O-])P(CCO)CCO</smiles>
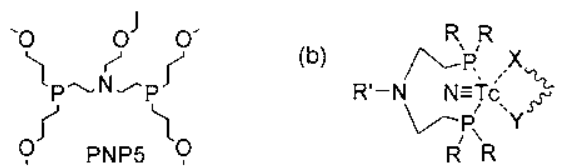

Figure 2: (a) The ligands "PNP and bifunctional fatty acid" and (b) general structure of asymmetrical nitride $\mathrm{Tc}(\mathrm{V})$ complexes.

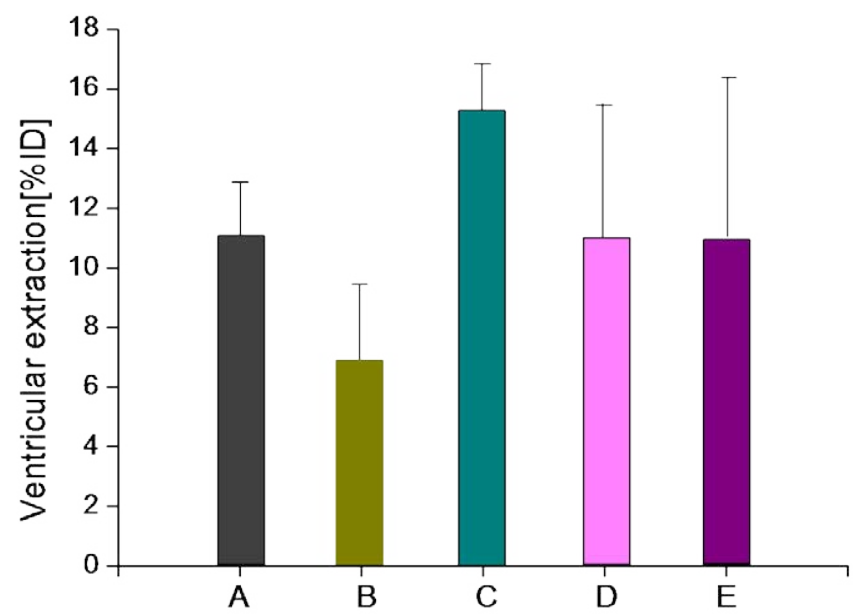

Figure 3: Ventricular extractions of the dodecanoic fatty acid complexes

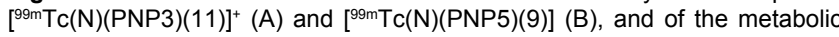

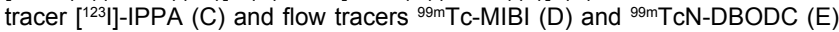
as determined in the same isolated perfused rat heart model.
3). Conversely, the ${ }^{99 \mathrm{~m} T c-l a b e l e d ~ f a t t y ~ a c i d ~ n e u t r a l ~ c o m p l e x e s ~ w e r e ~ n o t ~}$ efficiently accumulated in heart and rapidly washed out. It indicates that the fatty acid analogue with the monopositive charge is more beneficial to myocardial uptake than neutral complexes. Comparison of the observed kinetic behavior of the ${ }^{99 \mathrm{~m}} \mathrm{Tc}$-labeled fatty acid neutral complexes in the isolated perfused rat heart model with that of the myocardial metabolic tracer [ $\left.{ }^{123} \mathrm{I}\right]-\mathrm{IPPA}$ revealed that the introduction of the metallic moiety partially hampers recognition of the ${ }^{99 \mathrm{~m}} \mathrm{Tc}$ labeled fatty acids by cardiac enzymes (Figure 3), and consequently, their behavior did not completely reflect myocardial metabolism.

Our group previously synthesized the ${ }^{99 \mathrm{~m}} \mathrm{Tc}$-labeled monocationic fatty acids, $\left[{ }^{99 \mathrm{~m}} \mathrm{Tc}(\mathrm{CO})_{3}\right]^{+}$-DPAHA and $\left[{ }^{99 \mathrm{~m}} \mathrm{Tc}(\mathrm{CO})_{3}\right]^{+}$-DPAUA (Figure 4), which showed higher initial myocardial uptake in normal mice, followed by slow clearance $[28,29]$. By estimating the animal experiments and the theoretical calculations of the molar volume and the solvation free energy of technetium-99m chelating groups, a small-size and monocationic technetium-99m core is beneficial to enhance the myocardial accumulation with high heart-to-blood uptake ratios (such as $\left[{ }^{99 \mathrm{~m}} \mathrm{Tc}(\mathrm{N})(\mathrm{PNP} 3)(\mathrm{L})\right]^{+}$) and reduce radioactivity accumulation in liver for the ${ }^{99 \mathrm{~m}} \mathrm{Tc}$-labeled fatty acids. From the higher initial myocardial uptake and slow clearance, the kinetic behavior of the monocationic complexes was much closer to that of the fatty acid analogues $\left[{ }^{99 \mathrm{~m}} \mathrm{Tc}(\mathrm{N})(\mathrm{PNP} 3)(11)\right]^{+}$than the myocardial metabolic tracer [ $\left.{ }^{123} \mathrm{I}\right]-\mathrm{IPPA}$. Another ${ }^{99 \mathrm{~m}} \mathrm{Tc}$-labeled hexadecanoic acid with $\left[{ }^{99 \mathrm{~m}} \mathrm{Tc}(\mathrm{N})\right.$ $(\mathrm{PNP})]^{2+}$ core resulting in a neutral complex [1] was reported that the asymmetric $[2+2]$ complex cleared faster from the non-target organs, namely, liver, lungs, and blood compared to that of [ $\left.{ }^{125} \mathrm{I}\right]$-IPPA. However, the compounds exhibited lower uptake and faster washout from the myocardium as compared to $\left.{ }^{[25} \mathrm{I}\right]-\mathrm{IPPA}$, which might have demonstrated again that the ${ }^{99 \mathrm{~m}} \mathrm{Tc}$-labeled fatty acid analogues with one monopositive charge are more advantageous to myocardial uptake and retention than the neutral ones, and their behaviors still did not completely reflect myocardial metabolism.

\section{“4 + 1" Mixed Ligand Technetium-99m-labeled Fatty Acid Analogues}

Technetium-labeled fatty acids for myocardial metabolism imaging were synthesized according to the " $4+1$ " mixed-ligand approach, where the metal core in the oxidation states +3 , well-wrapped in a trigonal-bipyramidal coordination moiety, is attached at the $\omega$-position of a fatty acid chain. Walther groups reported a series of " $4+1$ " mixed ligand ${ }^{99 \mathrm{~m}} \mathrm{Tc}$-labeled fatty acids (Figure $5 \mathrm{a}$ ), which the technetium-99m is coordinated by both a tetradentate NS3 chelator and a monodentate isocyano fatty acid coligand with different chain length [30]. The tracers all showed high ventricular extraction rates in isolated perfused rat hearts (up to $26 \% \mathrm{ID}$ ), which exceed considerably that of the iodinated fatty acid [ $\left.{ }^{123} \mathrm{I}\right]$-IPPA (15.51\%ID). In particular, the tracer C11S [29] had a noticeable heart uptake of $2 \% \mathrm{ID} / \mathrm{g}$ at $5 \mathrm{~min}$ pi and a good heart to blood ratio of 8.6 at $5 \mathrm{~min}$ pi in biodistribution studies, which is superior to other described ${ }^{99 \mathrm{~m}} \mathrm{Tc}$-fatty acid mimics. The heart to liver ratio of 0.25 at $5 \mathrm{~min}$ pi was improved, which indicated that the

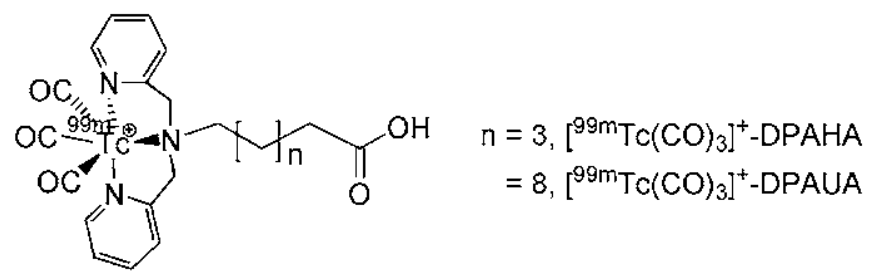

Figure 4: The structure of $\left[{ }^{99 \mathrm{~m}} \mathrm{Tc}(\mathrm{CO})_{3}\right]^{+}$-DPAHA and $\left[{ }^{99 \mathrm{~m}} \mathrm{Tc}(\mathrm{CO})_{3}\right]^{+}$-DPAUA. 
(a)

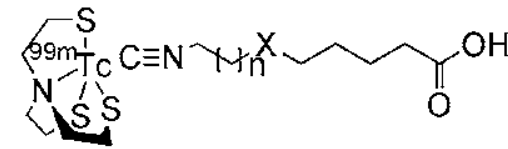

(c)<smiles>O=C(O)CCCCCCSC1CCCCS1</smiles>

(b)

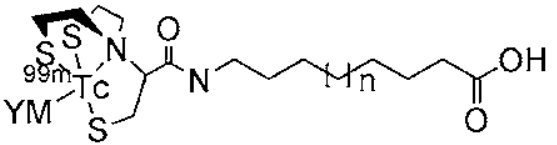

$n=1-10 ; E=N M e, S ;$

$\mathrm{X}=\mathrm{CH}_{2}, \mathrm{~S}$;

$M Y=$ isocyano ligand or

monodentate phosphine

Figure 5: General formula for ' $4+1$ ' (a), (b) and ' $3+1$ ' (c) ${ }^{99 m}$ Tc-labeled fatty acids.

biobehavior of the tracers may depend on the variations between the " $4+1$ " binding mode and the chelate position in the fatty acid chain.

For improving myocardial profile and accelerating liver clearance, the ${ }^{99 \mathrm{~m}} \mathrm{Tc}$-chelate was transferred to a more central position of the " $4+$ 1 " ${ }^{99 \mathrm{~m}}$ Tc-labeled fatty acid. Twenty nine modified " $4+1$ " ${ }^{99 \mathrm{~m}} \mathrm{Tc}$-labeled fatty acids (Figure $5 b$ ) were synthesized following a new permutation: carboxylic group, alkyl chain, Tc-chelate, and lipophilic tail [31]. The length of the fatty acid chain varied among $1,8,12$, and 15 carbon atoms. The highest value of ventricular extraction in the isolated perfused Langendorff rat heart was achieved with up to $20 \%$ ID and a rapid liver clearance followed by only $0.29 \% \mathrm{ID} / \mathrm{g}$ at $60 \mathrm{~min} \mathrm{pi}$, which indicated that the induced molecular modifications affect the kinetics of ${ }^{99 \mathrm{~m}} \mathrm{Tc}$ radiolabeled fatty acids favorably. In addition, the compound exhibited a higher ventricular extraction value than that of $\left[{ }^{125} \mathrm{I}\right]$-IPPA with 15.5 \%ID. Rapid clearance from blood was observed in the biodistribution for all investigated compounds. However, no compound shows both a high myocardial uptake and an accelerated washout from the liver. Thus, the heart to liver ratio could not be improved by the accomplished alterations of the fatty acid binding mode to the " $4+1$ " chelate unit and variations of the chelate position in the fatty acid chain. Although a clear structure-biobehavior relationship is still missing, some important rules were objectified [30].

The ' $3+1$ ' mixed-ligand approach for technetium-labeled fatty acid (Figure $5 \mathrm{c}$ ) is similar to the ' $4+1$ ' mode, which the metal core in the oxidation states +5 is wrapped with both a tridentate component consisting of the sulfido-dithiolate donor and a monodentate sulfhydryl group at the end position of fatty acid chain [32-34]. The ' 3 +1 ' and the ' $4+1$ ' mixed-ligand technetium-labeled fatty acids were investigated by the biodistribution in guinea pigs and and the isolated heart model [31]. The ' $4+1$ ' fatty acids showed the highest uptake rates and a higher ventricular extraction of the applied activity than BMIPP, IPPA, ${ }^{99 \mathrm{~m}} \mathrm{Tc}-\mathrm{MIBI}$ and the ' $3+1$ ' fatty acids. Furthermore, the thiadodecanoic acids showed a good heart to blood and heart to lung ratio and also a high uptake in the liver. The excellent extraction rates of the ' $4+1$ ' fatty acids, which depends on the fatty acid chain length and structure, indicate possibly promising structures for myocardial tracers.

\section{${ }^{99 m} \mathrm{Tc}(\mathrm{CO})_{3}$-labeled Fatty Acid Analogues}

A tricarbonyl technetium-labeled fatty acid analogue was prepared by incorporating fatty acid into a tridentate chelating moiety, then radiolabeling with the $\left[{ }^{99 \mathrm{~m}} \mathrm{Tc}(\mathrm{CO})_{3}\left(\mathrm{H}_{2} \mathrm{O}\right)_{3}\right]^{+}$precursor. According to the approach, ${ }^{99 \mathrm{~m}} \mathrm{Tc}-\mathrm{PA}-\mathrm{PA}$ was synthesized in high yield by incorporating $\left[{ }^{99 \mathrm{~m}} \mathrm{Tc}(\mathrm{CO})_{3}\right]^{+}$into a tridentate pentadecanoic acid (Figure 6a), showing its high chemical stability in human plasma [18]. An in vivo evaluation of ${ }^{99 \mathrm{~m} T c-P A-P A}$ demonstrated that high radioactivity accumulated
(6.38 \% ID/g at $1 \mathrm{~min}$ and $0.73 \% \mathrm{ID} / \mathrm{g}$ at $5 \mathrm{~min}$ pi.) in the heart with rapid clearance in the fasting state of mice. The maximum heart to blood uptake ratio was 1.87 at $5 \mathrm{~min}$ after a tail-vein injection. Radioactive metabolites were analyzed in urine samples of mice and corresponded to a 9.3:1 ratio of ${ }^{99 \mathrm{~m}} \mathrm{Tc}-(\mathrm{CO})_{3}-5$-[ $\mathrm{N}$-(acetyloxy)-2-picolylamino] pentanoic acid ( $\left.{ }^{99 \mathrm{~m}} \mathrm{Tc}-\mathrm{PA}-\mathrm{PtA}\right)$ (Figure 6a) to ${ }^{99 \mathrm{~m}} \mathrm{Tc}(\mathrm{CO})_{3}-3-[\mathrm{N}-$ (acetyloxy)-2-picolylamino]-propionic acid ( ${ }^{99 \mathrm{~m} T c-P A-P r A)}$ (Figure $6 \mathrm{a})$, indicating that ${ }^{99 \mathrm{~m}} \mathrm{Tc}-\mathrm{PA}-\mathrm{PA}$ is mainly metabolized to ${ }^{99 \mathrm{~m}} \mathrm{Tc}-(\mathrm{CO})_{3}$ 5-[N-(acetyloxy)-2-picolylamino]pentanoic acid via beta-oxidation in the body, indicating that ${ }^{99 \mathrm{~m}} \mathrm{Tc}$-PA-PA was metabolized beta-oxidation by removing two-carbon units (Figure 6).

Long-chain fatty acids are highly lipophilic to localize in the liver, constituting favorable vectors for this modality of diagnosis and treatment. Radiolabeled lipophilic complexes suspended in lipophilic medium of lipiodol have been used successfully in the detection and treatment of hepatocellular carcinoma. Among them, ${ }^{131}$ I-lipiodol is a commercially available FDA-approved agent. The lipophilic complex, ${ }^{99} \mathrm{~m} \mathrm{Tc}(\mathrm{CO}){ }_{3}$-PA-PEDA (Figure $6 \mathrm{~b}$ ), was prepared in $>95 \%$ radiochemical yield by incorporating $\left[{ }^{99 \mathrm{~m}} \mathrm{Tc}-(\mathrm{CO})_{3}\right]^{+}$into pentadecanoic acid with a tridentate N3 chelator [35]. This labeling method can be extended to Re-188 for preparing a therapeutic radiopharmaceutical. ${ }^{99 \mathrm{~m}} \mathrm{Tc}(\mathrm{CO})_{3-}$ PA-PEDA was stable in vitro under atmospheric conditions as well as in serum at $37^{\circ} \mathrm{C}$. The partition coefficient $(\log \mathrm{P})$ of ${ }^{99 \mathrm{~m}} \mathrm{Tc}(\mathrm{CO})_{3}$-PAPEDA in octanol and water was determined to be 1.5 , which suggests that it is lipophilic. The tracer ${ }^{99 \mathrm{~m}} \mathrm{Tc}(\mathrm{CO})_{3}$-PA-PEDA had a high initial liver uptake of up to $50 \%$ ID/organ at $10 \mathrm{~min}$ pi and a low liver uptake of $23.5 \% \mathrm{ID} /$ organ at $3 \mathrm{~h}$ pi in mice. However, the liver uptake of the lipiodol suspension of the complex reached $43.8 \pm 13.4 \%$ ID/organ at 3 $\mathrm{h}$ pi and $23.8 \pm 3.5 \% \mathrm{ID} /$ organ at $3 \mathrm{~h}$ pi in rats via the portal vein. The lower uptake of the complex in the liver and rapid clearance suggested that a suitable modification is need in chain length and lipophilicity of bifunctional chelating agent.

\section{Challenges and Directions}

In aerobic conditions, the fatty acid oxidations supply the myocardium with about two-thirds or more of the total energy, and a reduction in fatty acid uptakes can reflect various pathological myocardium such as ischaemia due to substrate shift from fatty acids to glucose. Accordingly, a variety of radiolabeled fatty acids have been introduced for SPECT/PET imaging. However, straight chain fatty acid analogues with their rapid washout and bi-exponential clearance have not been used widely for SPECT/PET imaging in clinical diagnosis. Thereby, BMIPP, introducing a methyl branching at the beta-carbon position, permit SPECT imaging more easily for their prolonged myocardial retention, which is the only fatty acid tracer approved for daily clinical use at present. However, BMIPP may not quantify its uptake and differentiate an ischaemic myocardium from a myocardial 
(a)

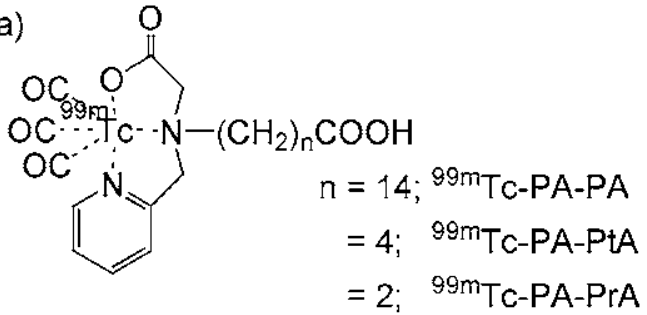

(b)

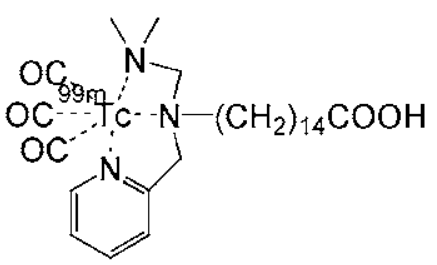

Figure 6: General structure for tricarbonyl ${ }^{99 \mathrm{~m} T c-l a b e l e d}$ fatty acids.

scar [36,37]. In addition, absence of uptake of BMIPP in a minority of patients without any significant cardiac abnormality raised the question of the mechanism of fatty acid transport into the cells [38]. Therefore the easy availability radionuclide Tc- $99 \mathrm{~m}$ acted as a surrogate to the iodide has been used to develop Tc-99m chelating fatty acid tracers, but so far the work are not quite smooth.

Technetium-labeled fatty acid analogues have been developed by introducing Tc-99m chelate to the terminal position of straight-chain fatty acid. Among all the ${ }^{99 \mathrm{~m}} \mathrm{Tc}$-labeled fatty acids, the half-life of aerobic beta-oxidation of these fatty acids is fast and in the order of minutes. The remainder of the total tracers incorporating into the lipid pool, mainly in the form of triglycerides and phospholipids, presents in the myocardium or liver for a long time. Turnover in the lipid pool is very slower, with a half-life of hours [4]. In addition, the introduction of metal chelate disturbs the inherent nature of the fatty acid, which alters the molecular structure and hydrophobicity compared with the natural compound. To overcome the problems including Tc-99m chelate resulting in a low uptake in myocardium or hepatocyte and linear alkyl chain based on beta-oxidation leading to a rapid clearance from tissues, technetium-labeled fatty acids are developed by varying the chelating ligand and branching alkyl chain of fatty acid (Figure 1). The common method prolonging myocardial/hepatic retention is metabolic trapping by inhibition of beta-oxidation through the introduction of methyl branching (or sulfur atoms) at the beta-carbon position. A Tc-99m core with high stability and relative small molecular size is very useful to abate the negative influences on the structure of fatty acids and enhances target organ uptakes of fatty acid analogues.

Recently, a variety of Tc-99m cores have been used for fatty acid tracers, such as $f a c-{ }^{99 \mathrm{~m}} \mathrm{Tc}(\mathrm{CO})_{3}\left(\mathrm{H}_{2} \mathrm{O}\right)_{3}{ }^{+}, f a c-\left[{ }^{99 \mathrm{~m}} \mathrm{Tc}(\mathrm{O}) \mathrm{MAMA}\right]$, $f a c-\left[{ }^{99 \mathrm{~m}} \mathrm{Tc}(\mathrm{N})(\mathrm{PNP})\right]^{2+}$, and so on, which are the very versatile moieties to react with various chelating fatty acids under their

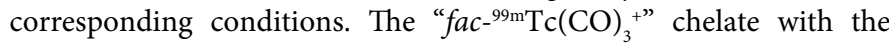
stability, significantly smaller size and easy synthesis offers exciting possibilities for fatty acid labeling [24]. Particularly, the diminutive and lipophilic cyclopentadienyl tricarbonyl Tc-99m core ${ }^{99 \mathrm{~m}} \mathrm{Tc}$ CpTT) only minimally perturbs biological activity of fatty acid. In the chelating groups of ${ }^{99 \mathrm{~m} T c-C p T T-P A}$ and ${ }^{99 \mathrm{~m}} \mathrm{Tc}-\mathrm{CpTT}-16$-oxo-HDA, $\omega$-cyclopentadienyl fatty acids chelated the $\mathrm{fac}^{-99 \mathrm{~m}} \mathrm{Tc}(\mathrm{CO})_{3}{ }^{+}$complex, which showed the tracers had high chemical stability in vitro and high initial radioactivity accumulation but with rapid myocardial washout and higher blood background than that of [ $\left.{ }^{125} \mathrm{I}\right]$ IPPA. However, the fatty acid tracers with other Tc-99m cores, such as ${ }^{99 m} \mathrm{Tc}-\mathrm{MAMA}-\mathrm{HA}$, $\left[{ }^{99 \mathrm{~m}} \mathrm{Tc}(\mathrm{N})(\mathrm{PNP} 3)(11)\right]^{+},\left[{ }^{99 \mathrm{~m}} \mathrm{Tc}(\mathrm{N})(\mathrm{PNP} 5)(9)\right],\left[{ }^{99 \mathrm{~m}} \mathrm{Tc}(\mathrm{CO}){ }_{3}\right]^{+}$-DPAUA, and so on, demonstrate lower uptake and target to nontarget ratio than [25I]-IPPA and bring other new disadvantages to fatty acid itself at the same time. Consequently, smaller size Tc-99m core for fatty acid is indispensable to overcome the perturbation and enhance uptake, and the insertion of blocking group for inhibition of $\beta$-oxidation may prolong myocardial/hepatic retention of fatty acid. Unfortunately, a series of branching alkyl chain of " $4+1$ " mixed-ligand technetium labeled fatty acids [30] has not been found in which both properties are combined properly. Thus, both diminutive Tc-99m core and blocking group are essential to improve the SPECT imaging quality with high uptakes and long retention of fatty acids.

\section{Acknowledgment}

This work was financially supported by the Research Fund for the Doctoral Program of Higher Education (20120101120039; 2012101120040) and the Doctoral Research Fund of Henan Chinese Medicine (BSJJ2012-08) and the Natural Science Foundation of Hebei Province of China (B2013402060).

\section{References}

1. Onishi S, Saibara T (2006) In vivo imaging of hepatic fatty acid metabolism in patients with non-alcoholic steatohepatitis using semiquantitative 123I-labeled branched-chain fatty acid analog. J Gastroenterol Hepatol 21 Suppl 3: S76-78.

2. Takala TO, Nuutila P, Pulkki K, Oikonen V, Gronroos T, et al. (2002) $14(\mathrm{R}, \mathrm{S})$ [18F]Fluoro-6-thia-heptadecanoic acid as a tracer of free fatty acid uptake and oxidation in myocardium and skeletal muscle. Eur J Nucl Med Mol Imaging 29: 1617-1622.

3. Liu Y (2006) Fatty acid oxidation is a dominant bioenergetic pathway in prostate cancer. Prostate Cancer Prostatic Dis 9: 230-234.

4. Taki J, Matsunari I (2007) Metabolic imaging using SPECT. Eur J Nucl Med Mol Imaging 34 Suppl 1: S34-48.

5. Bergmann SR, Weinheimer CJ, Markham J, Herrero P (1996) Quantitation of myocardial fatty acid metabolism using PET. J Nucl Med 37: 1723-1730.

6. Nellis SH, Liedtke AJ, Renstrom B (1992) Fatty acid kinetics in aerobic myocardium: characteristics of tracer carbon entry and washout and influence of metabolic demand. J Nucl Med 33: 1864-1874.

7. Bennett MJ (1994) The enzymes of mitochondrial fatty acid oxidation. Clin Chim Acta 226: 211-224.

8. Pandey MK, Bansal A, DeGrado TR (2011) Fluorine-18 labeled thia fatty acids for PET imaging of fatty acid oxidation in heart and cancer. Heart Metab 51:1519.

9. Tamaki N, Morita K, Kuge $\mathrm{Y}$, Tsukamoto $\mathrm{E}$ (2000) The role of fatty acids in cardiac imaging. J Nucl Med 41: 1525-1534.

10. Rosamond TL, Abendschein DR, Sobel BE, Bergmann SR, Fox KA (1987) Metabolic fate of radiolabeled palmitate in ischemic canine myocardium implications for positron emission tomography. J Nucl Med 28: 1322-1329.

11. Wyns W, Schwaiger M, Huang SC, Buxton DB, Hansen H, et al. (1989) Effects of inhibition of fatty acid oxidation on myocardial kinetics of 11C-labeled palmitate. Circ Res 65: 1787-1797.

12. Takala TO, Nuutila P, Pulkki K, Oikonen V, Gronroos T, et al. (2002) 14(R,S)[18F]Fluoro-6-thia-heptadecanoic acid as a tracer of free fatty acid uptake and oxidation in myocardium and skeletal muscle. Eur J Nucl Med Mol Imaging 29: 1617-1622.

13. lozzo P, Turpeinen AK, Takala T, Oikonen V, Solin O, et al. (2003) Liver uptake of free fatty acids in vivo in humans as determined with 14( R, S)-[18F]fluoro-6thia-heptadecanoic acid and PET. Eur J Nucl Med Mol Imaging 30: 1160-1164.

14. Karmi A, lozzo P, Viljanen A, Hirvonen J, Fielding BA, et al. (2010) Increased brain fatty acid uptake in metabolic syndrome. Diabetes 59: 2171-2177.

15. Bergmann SR (2007) Imaging of myocardial fatty acid metabolism with PET. J Nucl Cardiol 14: S118-124. 
16. Knapp FF Jr, Franken P, Kropp J (1995) Cardiac SPECT with iodine-123labeled fatty acids: evaluation of myocardial viability with BMIPP. J Nucl Med 36: $1022-1030$

17. Magata Y, Kawaguchi T, Ukon M, Yamamura N, Uehara T, et al. (2004) A TC$99 \mathrm{~m}$-labeled long chain fatty acid derivative for myocardial imaging. Bioconjug Chem 15: 389-393.

18. Lee BC, Kim DH, Lee JH, Sung HJ, Choe YS, et al. (2007) 99mTc(CO)3-15[N-(Acetyloxy)-2-picolylamino]pentadecanoic acid: a potential radiotracer for evaluation of fatty acid metabolism. Bioconjug Chem 18: 1332-1337.

19. Uehara T, Uemura T, Hirabayashi S, Adachi S, Odaka K, et al. (2007) Technetium-99m-labeled long chain fatty acid analogues metabolized by betaoxidation in the heart. J Med Chem 50: 543-549.

20. Lee BC, Kim DH, Lee I, Choe YS, Chi DY, et al. (2008) 16-Cyclopentadienyl tricarbonyl 99mTc 16-oxo-hexadecanoic acid: synthesis and evaluation of fatty acid metabolism in mouse myocardium. J Med Chem 51: 3630-3634.

21. Eckelman WC, Karesh SM, Reba RC (1975) New compounds: fatty acid and long chain hydrocarbon derivatives containing a strong chelating agent. J Pharm Sci 64: 704-706.

22. Karesh SM, Eckelman WC, Reba RC (1977) Biological distribution of chemical analogs of fatty acids and long chain hydrocarbons containing a strong chelating agent. J Pharm Sci 66: 225-228.

23. Benny PD, Moore AL (2011) Recent Advances in the Probe Development of Technetium-99m Molecular Imaging Agents. Curr Org Synth 8: 566-583.

24. Yamamura N, Magata $\mathrm{Y}$, Arano $\mathrm{Y}$, Kawaguchi T, Ogawa K, et al. (1999) Technetium-99m-labeled medium-chain fatty acid analogues metabolized by beta-oxidation: radiopharmaceutical for assessing liver function. Bioconjug Chem 10: 489-495.

25. Lee BC, Choe YS, Chi DY, Paik JY, Lee KH, et al. (2004) 8-cyclopentadienyltricarbonyl 99mtc 8-oxooctanoic acid: a novel radiotracer for evaluation of medium chain fatty acid metabolism in the liver. Bioconjug Chem 15: $121-127$

26. Zeng H, Zhang $H(2014)$ Synthesis and biological evaluation of fatty acids conjugates bearing cyclopentadienyl-donors incorporated [99mTc/Re(CO)3]+ for myocardical imaging. Eur J Med Chem 72: 10-17.

27. Cazzola E, Benini E, Pasquali M, Mirtschink P, Walther M, et al. (2008) Labeling of fatty acid ligands with the strong electrophilic metal fragment $[99 \mathrm{mTc}(\mathrm{N})$ $(P N P)] 2+(P N P=$ diphosphane ligand). Bioconjug Chem 19: 450-460.
28. Zeng H, Zhao L, Hu S, Liu Y, Yu H, et al. (2013) Synthesis, characterization and biodistribution of new fatty acids conjugates bearing N,N,N-donors incorporated [99mTc/Re(CO)3]+. Dalton Trans 42: 2894-2901.

29. Mathur A, Subramanian S, Mallia MB, Banerjee S, Samuel G, et al. (2008) Synthesis and bio-evaluation of a new fatty acid derivative for myocardial imaging. Bioorg Med Chem 16: 7927-7931.

30. Walther M, Jung CM, Bergmann R, Pietzsch J, Rode K, et al. (2007) Synthesis and biological evaluation of a new type of $99 \mathrm{mtechnetium-labeled} \mathrm{Fatty} \mathrm{Acid} \mathrm{for}$ myocardial metabolism imaging. Bioconjug Chem 18: 216-230.

31. Mirtschink P, Stehr SN, Pietzsch HJ, Bergmann R, Pietzsch J, et al. (2008) Modified "4 + 1" mixed ligand technetium-labeled fatty acids for myocardial imaging: evaluation of myocardial uptake and biodistribution. Bioconjug Chem 19: 97-108.

32. Heintz AC, Jung CM, Stehr SN, Mirtschink P, Walther M, et al. (2007) Myocardial uptake and biodistribution of newly designed technetium-labelled fatty acid analogues. Nucl Med Commun 28: 637-645.

33. Jung CM, Kraus W, Leibnitz P, Pietzsch HJ, Kropp J, et al. (2002) Syntheses and First Crystal Structures of Rhenium Complexes Derived from ?-Functionalized Fatty Acids as Model Compounds of Technetium Tracers for Myocardial Metabolism Imaging. Eur J Inorg Chem 1219-1225.

34. Maresca KP, Shoup TM, Femia FJ, Burker MA, Fischman A, et al. (2002) Synthesis, characterization, and biodistribution of a Technetium- $99 \mathrm{~m}$ ' $3+1$ ' fatty acid derivative. The crystal and molecular structures of a series of oxorhenium model complexes. Inorg Chim Acta 338: 149-156.

35. Satpati D, Pandey U, Sarma HD, Venkatesh M, Banerjee S (2009) Preparation and evaluation of $99 \mathrm{mTc}(\mathrm{CO}) 3$-labeled pentadecanoic acid derivative and its suspension in lipiodol. Cancer Biother Radiopharm 24: 503-507.

36. Biswas SK, Sarai M, Hishida H, Ozaki Y (2009) 123I-BMIPP fatty acid analogue imaging is a novel diagnostic and prognostic approach following acute myocardial infarction. Singapore Med J 50: 943-948.

37. Tamaki N, Tadamura E, Kudoh T, Hattori N, Yonekura Y, et al. (1996) Prognostic value of iodine-123 labelled BMIPP fatty acid analogue imaging in patients with myocardial infarction. Eur J Nucl Med 23: 272-279.

38. Hwang EH, Yamashita A, Takemori H, Taki J, Nakajima K, et al. (1996) Absent myocardial I-123 BMIPP uptake in a family. Ann Nucl Med 10: 445-448. 